\title{
Autoconhecimento e reflexões sobre a vida
}

DOI: dx.doi.org/10.18616/nrm02

Cristiane Damiani Tomasi Bruna Giassi Wesller Lisiane Tuon

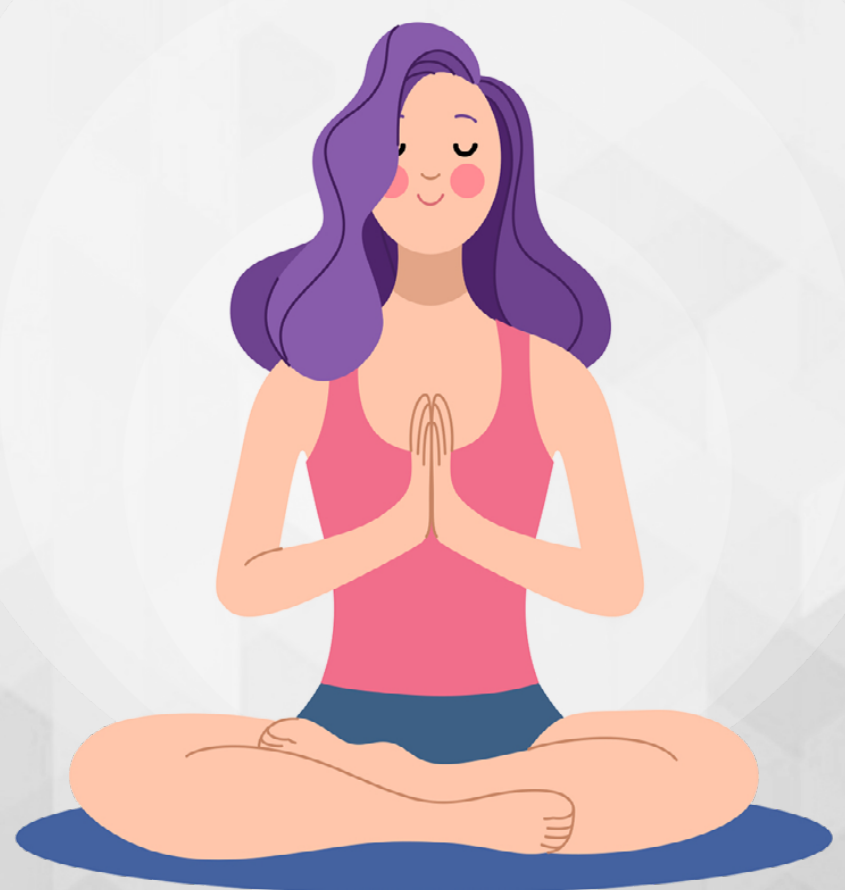


Em tempos de isolamento social, muitos termos associados à saúde e ao bem-estar da população vêm sendo discutidos. Abaixo seguem algumas definições.

\section{Felicidade}

Satisfação subjetiva com nossa vida, que incorpora tanto a experiência emocional de sentir-se bem ou experiências prazerosas quanto a percepção de viver uma vida boa e com significado, cada vez mais sendo vista como um modo de avaliar o sucesso em uma sociedade.

\section{Bem-estar}

Evolução subjetiva de satisfação de vida. Uma definição mais ampla pode considerar, de forma menos subjetiva, as circunstâncias sociais e pessoais que podemos considerar para contribuir para uma boa vida.

\section{Qualidade de vida}

Percepção pessoal de nossa posição na vida no contexto de um sistema e de uma cultura de valor e em relação aos nossos objetivos, padrões e conceitos e às expectativas (WHOQOL GROUP, 1995).

\section{Saúde mental}

Capacidade de pensamento, emocional e comportamental, que permite a cada pessoa perceber seu próprio potencial em relação ao estágio de desenvolvimento, lidar com o estresse normal da vida, estudar ou trabalhar de modo produtivo e de modo proveitoso, bem como contribuir para a comunidade.

\section{Sofrimento social}

As formas como os componentes de sofrimento são enraizados em situações sociais e condicionados pela cultura local.

\section{Resiliência}

Capacidade de nos adaptarmos às situações de adversidade ou de estresse, incluindo a capacidade de lidar com eventos negativos futuros. 


\section{EXERCÍCIOS DE AUTOCONHECIMENTO}

A meditação parece ser um bom caminho para o autoconhecimento. Aqui selecionamos alguns aplicativos que poderão ajudar você nesse caminho. Eles poderão ser acessados pelas lojas virtuais de alguns smartphones ou empresas (APPLE; SAMSUNG, GOOGLE, 2020).

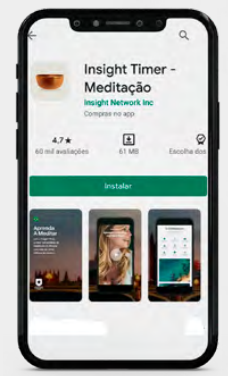

Insight Timer

Meditação - para acalmar a mente, reduzir a ansiedade, controlar o estresse, ajudar a dormir profundamente e aumentar o nível de felicidade. O app tem meditações e palestras guiadas lideradas por especialistas em mindfulness. Também possui faixas de músicas e sons ambientes, bem como grupos de discussão (INSIGHT NETWORK INC, 2020).

\section{Instalar Android}

\section{Instalar IOS}

\section{Headspace}

Headspace:

Meditação e

Mindfulness

Meditação e Sono - ensina a respirar, meditar e viver com atenção plena. Contém exercícios para ajudar a controlar a ansiedade, aliviar o estresse, melhorar a respiração e viver com mais felicidade, calma e concentração. Em "adormecer", você encontrará meditações para dormir, músicas relaxantes e sleepcasts para guiar seu descanso (HEADSPACE, 2020).

\section{Instalar Android}

\section{Instalar IOS}

\section{Spotify}

O Spotify é um aplicativo de músicas, que você pode utilizar em seu navegador de internet ou no celular (SPOTIFY LTDA., 2020).

Você sabia que, além de músicas, esse aplicativo conta

com vários podcasts? Aqui selecionamos algumas dicas de podcasts que você poderá ouvir, que poderão fazê-lo(a) refletir sobre a vida, buscar o autoconhecimento e meditar.

\section{Instalar Android}

\section{Instalar IOS}


Autoconhecimento e reflexões sobre a vida

\section{Meditação Pura}

\section{Energia Positiva}

Em um dos mais reconhecidos podcasts da categoria espiritual, acompanhe Vanessa Scott e seu método único de promover o bem-estar por meio da

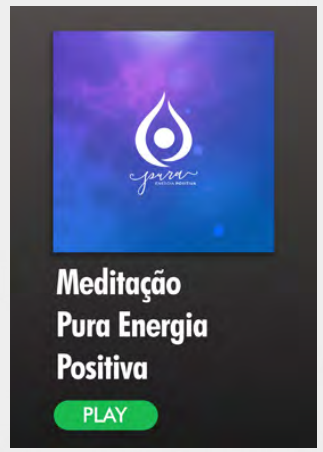
lei da atração, positividade e de mindfulness. Com conteúdos novos, apresentados semanalmente, você despertará sua paz interior e obterá explicações de como conseguir equilíbrio emocional, sono profundo, dentre outros benefícios comprovados cientificamente. Com a mente calma e presente no momento, você estará equipado para vencer todos os desafios da vida, incluindo o estresse e a ansiedade. Viva melhor com as meditações guiadas da Pura Energia Positiva. Em todas as segundas, quartas e sextas-feiras, sempre um novo episódio.

\section{Despertar Zen}

Palestras da Monja Coen, gravadas no templo Tenzui Zenji da comunidade ZEN do Brasil.

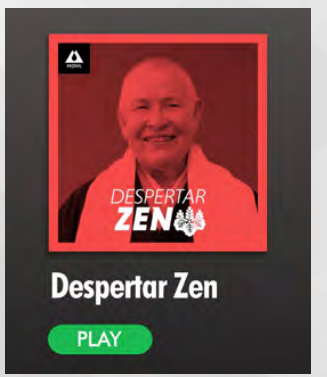

Espiritualidade, Consciência e Evolução

Por meio desse podcast, você encontrará os mais diversos assuntos sobre Espiritualidade, Comportamento e Desenvolvimento Humano, abordados pelo fundador do Centro de Estudos da Consciência, Moisés Esagui, uma associação não governamental e sem fins lucrativos. Os materiais postados são programas de rádio, TV e diversos outros também presentes em nossos canais no Youtube. Assuntos: Projeção Astral/Viagem Astral, Chacras, Bioenergias, Clarividência, Autodefesa, Cura, Imposição de Mãos, O Domínio das Emoções etc.

\section{Tudo é Cura}

Podcast sobre a vida, com conteúdo voltado a assuntos de bem-estar, saúde, comportamento e autodesenvolvimento para uma vida leve, criativa e amorosa consigo e

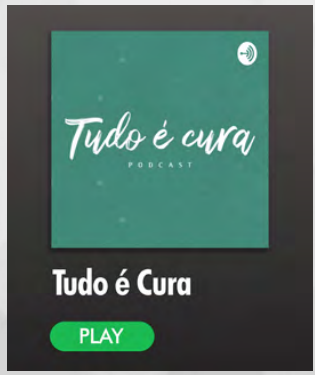
com o mundo. 


\section{Estamos Bem?}

Toda segunda-feira, os jornalistas Bárbara dos Anjos Lima e Thiago Theodoro convidam você para embarcar em uma jornada de autoconhecimento em busca de jeitos mais legais

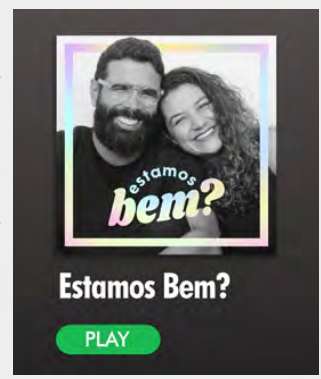
e leves de viver a vida. Venha com a gente!
Na Nossa Vida

A youtuber, podcaster, instagrammer e escritora Isa Ribeiro compartiIha o seu guia para uma vida mais leve e para falar da vida. Espera inspirar você a se apaixonar

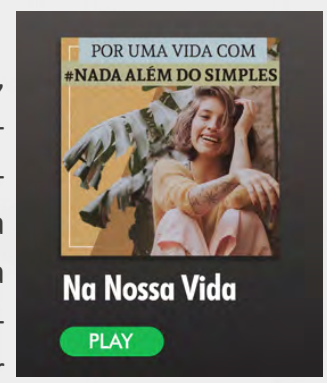
pelas pequenas coisas do dia a dia. Tudo que acontece na sua, na nossa vida. Tudo por uma vida com \#NadaAlémdoSimples.

\section{Autoconsciente}

Podcast que entende você e busca auxiliá-lo(a) a entender melhor a sua mente e as suas emoções para que possa ter uma relação mais leve consigo mesmo(a), baixando o tom da autocobrança e da autocrítica que ecoa na sua cabeça, e encontrar, dentro de si, a paz que está tão difícil de ser encontrada no mundo.

Autoconsciente é um bom lugar para se estar nestes nossos tempos conturbados. Seus episódios retratam situações que todos nós vive-

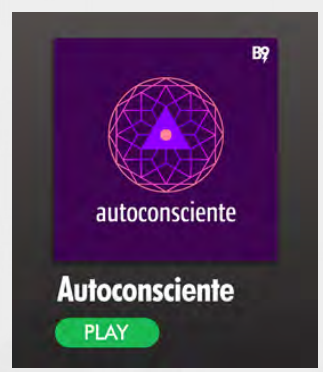
mos, com uma abordagem esclarecedora, acolhedora e reenergizante. Mais do que um conteúdo, você encontrará uma experiência pacificadora.
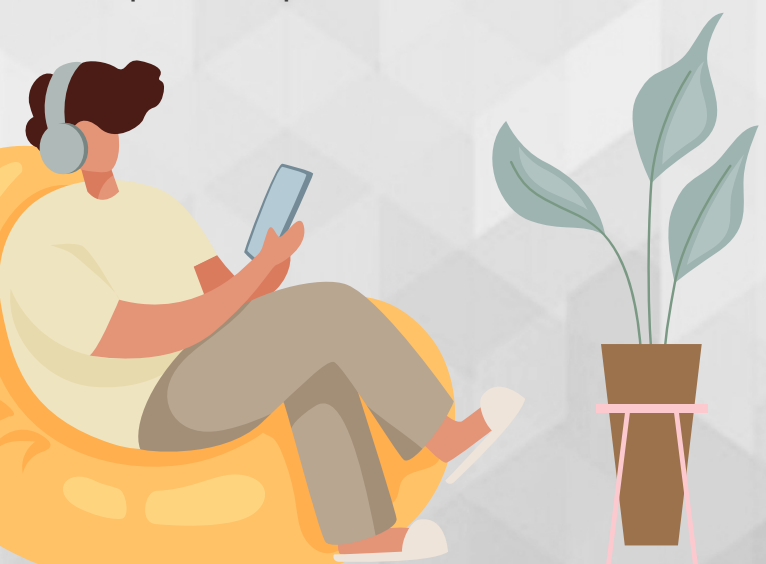